\title{
12 years Editor-in-Chief: Hans G. Beger
}

\author{
Thilo Welsch • Markus W. Büchler
}

Published online: 9 June 2010

(C) Springer-Verlag 2010

Langenbeck's Archives of Surgery just celebrated an impressive 150th anniversary, making it the oldest as well as a beacon of tradition for surgical journals. The history of Langenbeck's Archives of Surgery had begun before leading journals like Annals of Surgery (1885) or British Journal of Surgery (1913) began. The outstanding tradition of the journal is ideally demonstrated by the revolutionary articles in the second half of the nineteenth century by surgical pioneers like Billroth, Kocher, Rehn, or later by Kausch and Sauerbruch [1]. The list of former editors of Langenbeck's includes the most distinguished and honored German surgeons who all contributed to major advancements of surgical patient care and who are still present in our daily surgical mind and practice [2].

Hans Beger has been the editor-in-chief for the last 12 years, and his presence continues to grace the list of honorary German surgeons. His surgical achievements were outstanding and the Beger procedure has become a standard procedure for patients with chronic pancreatitis and other benign pancreatic diseases and is applied and referenced today world-wide [3]. Hans Beger took over the editor-inchief position in 1998 when the journal's name was Langenbeck's Archiv für Chirurgie. Langenbeck's was a German-language publishing journal with an impact factor of 0.97 at that time. He realized that Langenbeck's merits much more international reputation than reflected by the mere impact factor, which would necessitate publication in English, the new lingua franca. Starting with volume 384,

T. Welsch • M. W. Büchler $(\triangle)$

Department of General, Visceral, and Transplantation Surgery,

University of Heidelberg,

Heidelberg, Germany

e-mail: markus.buechler@med.uni-heidelberg.de
Langenbeck's Archives of Surgery was an English-language publishing journal and restructured to become a highquality, informative, competitive, and attractive international surgical journal. The main foci of the journal were GI tract diseases and endocrine surgery. Newly designed journal sections to support bench-to-bedside research ("New surgical horizons") or minimal invasive surgery and educational aspects ("How-to-do-it") were introduced. From the beginning, Hans Beger aimed to increase the proportion of international contributions to the journal and invited internationally leading surgeons to the editorial board. Moreover, peer reviews were performed by both experienced German and international reviewers. Hans Beger also successfully managed to transform Langenbeck's into an electronic publishing and operating journal. All of those changes to the journal resulted in a continuous increase in submitted articles per year (321 in 2009) and in over 140,000 electronic full paper downloads in the last year. Finally, the impact factor of the journal was raised from 0.97 to 1.577 under Editor-in-Chief Beger [4].

Hans Beger has not only edited a traditional surgical journal but has significantly shaped Langenbeck's Archives of Surgery in the last 12 years. His status as an internationally accepted leading mind in the field of academic surgery has made this possible. Today, he has produced more than 750 original scientific papers and is an active member in more than 20 international journals. He will proceed to live and practice academic surgery in the future.

The international surgical community and the readership of Langenbeck's would like to thank Hans Beger for his great contribution to the journal and to the progress of current surgery. He prepared Langenbeck's to be established within the top international surgical periodicals for the next decades. 


\section{References}

1. Beger HG, Gansauge F (2010) Master of surgery in Archiv für Klinische Chirurgie. Langenbecks Arch Surg 395:S17S2 1

2. Rau BM (2010) The editors of Langenbeck's since 1860. Langenbecks Arch Surg 395:S13-S16
3. Köninger J, Seiler CM, Sauerland S, Wente MN, Reidel MA, Müller MW, Friess H, Büchler MW (2008) Duodenum-preserving pancreatic head-resection - a randomized controlled trial comparing the original Beger procedure with the Berne modification (ISRCTN No. 50638764). Surgery 142:490-498

4. Beger HG (2010) From Archiv für Klinische Chirurgie to Langenbeck's Archives of Surgery: 1860-2010. Langenbecks Arch Surg 395:S3-S12 